\title{
A perspective on the editorial by Ken Gillman: "Much ado about nothing': monoamine oxidase inhibitors, drug interactions, and dietary tyramine"
}

\author{
Sue Trupin*
}

Currently retired; formerly of the General Medical Clinic, San Francisco General Hospital, San Francisco, California, USA

First published online 19 June 2017

March 1, 2017

Dr. Stahl,

As an experienced health professional who has suffered serious depression, I wish to strongly endorse your February 2017 editorial, "Much ado about nothing: monoamine oxidase inhibitors, drug interactions, and dietary tyramine," by Dr. Ken Gillman.

In my mid-60s I endured by far my most severe episode, which persisted for more than 3 years. I was treated with all the usual combinations and augmentations with minimal to no relief. I was hospitalized twice and received a 12-session course of ECT, also with minimal response. When I announced to my psychiatrist that I had tapered myself off my meds, she started me on tranylcypromine, to which I responded unequivocally within a week or two. The side effects were manageable and temporary. I sorted out the food restrictions and drug interactions on my own, eventually coming to the same basic conclusions discussed in Dr. Gillman's editorial. I have been well now for about 3 years.

I am, however, increasingly appalled by the disregard in which these inexpensive and highly efficacious medicines are held. They appear essentially to have been removed from the pharmacopoeia as far as the majority of clinicians are concerned. I have come reluctantly to the conclusion that the bias against MAOIs is so entrenched in the psychiatric profession, it will likely be patients and their loved ones who turn this prejudice around.

Dr. Gillman's editorial hopefully will elicit amongst your readers a sincere re-evaluation of the risks with which these stalwart medicines have so unfortunately and erroneously been defined.

Sue Trupin, RN

San Francisco, CA

* Address for correspondence: Sue Trupin RN, 389 Day St. San Francisco, CA 94131 USA. (Email: strupin@aol.com) 